\title{
A Study of the Inherited Relations between Classical Mythology and the Making of Chinese Animation Films
}

\author{
Hai Tang, Xiaobin Gong \\ MY Studio, Jiangnan University, Wuxi, China \\ Email: carlatube@qq.com
}

How to cite this paper: Tang, H., \& Gong, X. B. (2021). A Study of the Inherited Relations between Classical Mythology and the Making of Chinese Animation Films. Advances in Applied Sociology, 11, 415-429. https://doi.org/10.4236/aasoci.2021.119037

Received: August 11, 2021

Accepted: September 6, 2021

Published: September 9, 2021

Copyright ( 2021 by author(s) and Scientific Research Publishing Inc. This work is licensed under the Creative Commons Attribution International License (CC BY 4.0).

http://creativecommons.org/licenses/by/4.0/ (c) (i) Open Access

\begin{abstract}
In the process of the development of Chinese animations, mythical themes have provided a variety of practical materials for the creation of animated films. The recent domestic movies such as Monkey King. Hero is Back (2015) and Ne Zha: I am the Destiny (2019) are cases in point, achieving great progress in both quality and box office in the film industry. It can be seen that Chinese mythology and the creation of animated films are closely related; while the previous animation works might focus on the educational significance in design characters, films were productive while they lack of fun or suspense at some point. In addition, the development of Chinese animation in previous years has also been impacted by American and Japanese animations, an academic worry is that, would the Chinese mythological themes in the process of adaptation be slightly lost? Then, how to understand the connection between Chinese myths and the creation of animations becomes a key subject for writing the paper. In other words, this paper will use content analyses to claim that creation of animation films is to inherit cultural elements of Chinese mythology. Such inheritance not only highlights the national spirit, but also advocates cultural communication, allowing audience to understand the essence of Chinese culture.
\end{abstract}

\section{Keywords}

Chinese Animations, Mythology, Analyses, Relations, Cultural Inheritance

\section{Chinese Myths and Animated Adaptations in China}

In recent years, Chinese animated films have achieved both box office and attention from audience such as the 2015 work Monkey King. Hero is Back and the 
2019 work Ne Zha: I am the Destiny. One reason for this popularity is that these animations are produced upon traditional Chinese mythology, combined them with modern thoughts and technology, and adapted them to be the masterpiece of Chinese animated works.

Starting with mythical themes, Chinese animation creators have been realizing how important it is when they merge narrative resources with national cultural attributes into the creation of their works. To some extent, exploring the cultural roots of China becomes the primary method for them to create animations. It can be seen that mythology is closely related to the formation and development of Chinese animated films.

Then, what kind of themes Chinese mythological stories have got, or how do Chinese animation filmmakers use mythology in narrating stories, further, to show national spirit? This is the question offered to be discussed in this paper.

This paper is divided into five parts. The first section briefly expounds the positivity and significance of Chinese myth on domestic animated film-making. The second section starts from the cultural elements of Chinese mythical stories to talk about productions of animated works. It points out that the myth brings about symbolic significance which is associated with cultural symbols of China. The third section analyses the storyline and artistic style of the animated works through content analyses, the aim is to further discuss how social values and beliefs can be disseminated through cultural immersion. It is undeniable that in the process of creating animations, Chinese movies have also been inspired by Japanese and American works. The next section talks about the impact of the two styles while at the same time, it points out that by learning from each other, China has set its sights on promoting animated products. The viewpoint is reinforced in the final section of this paper. That is, to understand cultural identity, and to highlight the importance of cultural communication in animation works.

\section{Mythology, Symbolism, and Film-Making}

With the development of digital technology, films based on the adaptation from myths and stories may relate to the term "reshaping". Examples such as Sun Wukong in the Monkey King. Hero is Back (2015) and Ne Zha in Ne Zha: I am the Destiny (2019) become popular, because the main characters are presented with radically different images. These films impress audiences with not only visual and special enjoyment, but also higher box offices in the market. As Li Xi argued in his work:

The narrative of the mythic text is broad and profound because the archetype and the area it covers are vast and extended. In other words, the mythical story is not a simple reading context, but a collection of mythological elements accumulated over thousands of years, which can activate the collective memory of a region or a nation (Li, 2010: p. 80).

From this point of view, the myths or mythical stories reflect ancient Chi- 
nese's original understanding of the world, the nature, along with their social life. Such understanding could be powerfully influential and it will be passed down from generation to generation (Luo, 2012: p. 130). The power of the magic of these myths means that ancient people did not have the ability to scientifically interpret natural phenomena or situations, however, because they fantasied of God and their beliefs in God helped them solve lots of problems in reality.

\subsection{An Educational Function of Mythical Stories}

Chinese are proud of the mythical theme of the so-called "Oriental" concept, and this can be seen from both the character of Sun Wukong or Ne Zha, as mentioned in the above section. The two characters are shaped as fighters and rebels; when they face misunderstanding, discrimination or injustice, they are determinate, they are likely to challenge the mainstream and they would never go drifting with the tide.

In addition to the challenger images like Sun Wukong and Ne Zha, in shaping female's image in animations, attentions are paid to high moral characteristics, along with love, hard work and kindness as personalities (Ding, 1996: p. 50). For example, Mulan in its animated film is not only shaped as a female hero and a brave solider, but also as a filial daughter, a lovely neighbor, and a selfless woman who sacrifices her life to save her family and her country (see Figure 1). These details reflect the nobleness and greatness of Chinese women.

It can be seen that Chinese myths, like Western magic stories, have offered instructive rooms to filmmakers for re-creating their movie characters and narrating their movie culture. The success of Lord of the Rings (see Figure 2), for example, lies in its absorption of the Norse mythology. Likewise, Harry Potter wins the audience because of the magic of witchcraft in its movie series. And, the story of Twilight takes place in a modern American town, but the related vampire culture shown in the movie has been accumulating Western people's interests for ages. In this sense, mythical stories function as practical resources to both

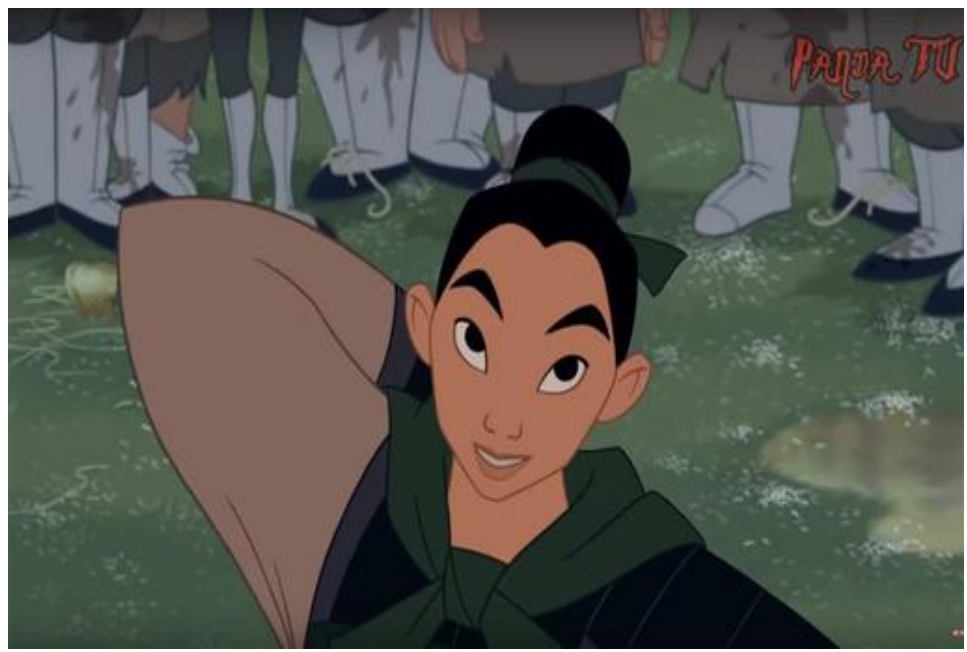

Figure 1. Mulan (source: http://image.baidu.com). 


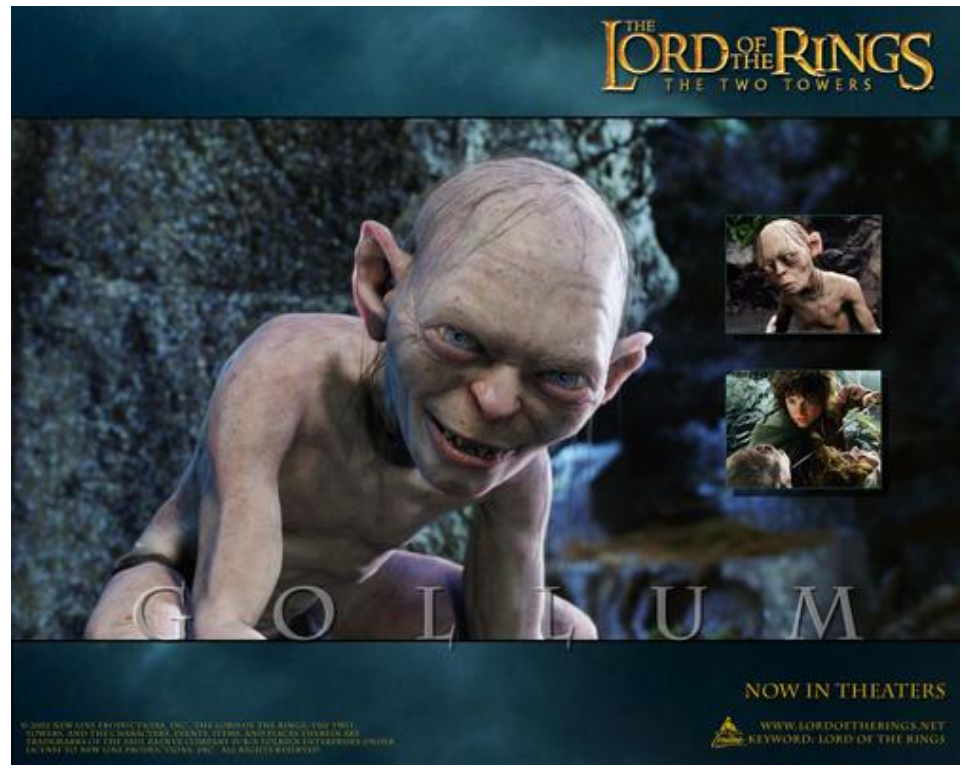

Figure 2. Lord of the Rings (source: http://image.baidu.com).

storyline and characters of a new animation.

\subsection{Symbolic Function of the Animated Films}

Looking back at the mythological stories of China, the images of the hero are taken from traditional Chinese myths. Sun Wukong, for example, is created from The Journey to the West, but the on-screen Sun Wukong does not appear as a monkey king only, the Five-Fingered Mountain where Sun Wukong was trapped under for 500 years (see Figure 3), along with the golden fillet (see Figure 4) and other scenes, they have provided implicated meanings. Five-Fingered Mountain can be seen as a symbol of the Rulai Buddha, and the golden ring headband can be seen as theocratic punishment for Sun Wukong's rebellion against the primacy of the heaven.

Thus, the image of Sun Wukong shaped around the environment and props, not only offers cultural contexts, but also has symbolic significance. Zhou Ying claimed that:

Symbols in a movie can be seen as tools for understanding media culture. It is generally believed that symbols are composed of two elements, the signifier and the signified. Together they constitute language of the film with both internal and external expressions (Zhou, 2016: p. 77).

If Sun Wukong's heroic image is based on his courage to challenge the authority of the Gods, the success of Ne Zha: I am the Destiny in 2019 may lie in the character who has subverted a traditional definition of God and Demon, and thus, it forms new spiritual value "I am the destiny" (Tang, 2021: p. 52). The following are two remarkable characters taken from the same myth story (see Figure 5 and Figure 6), however, when the original signifier of a mythical story is given signified meaning in its animated version, the characters will be offered 


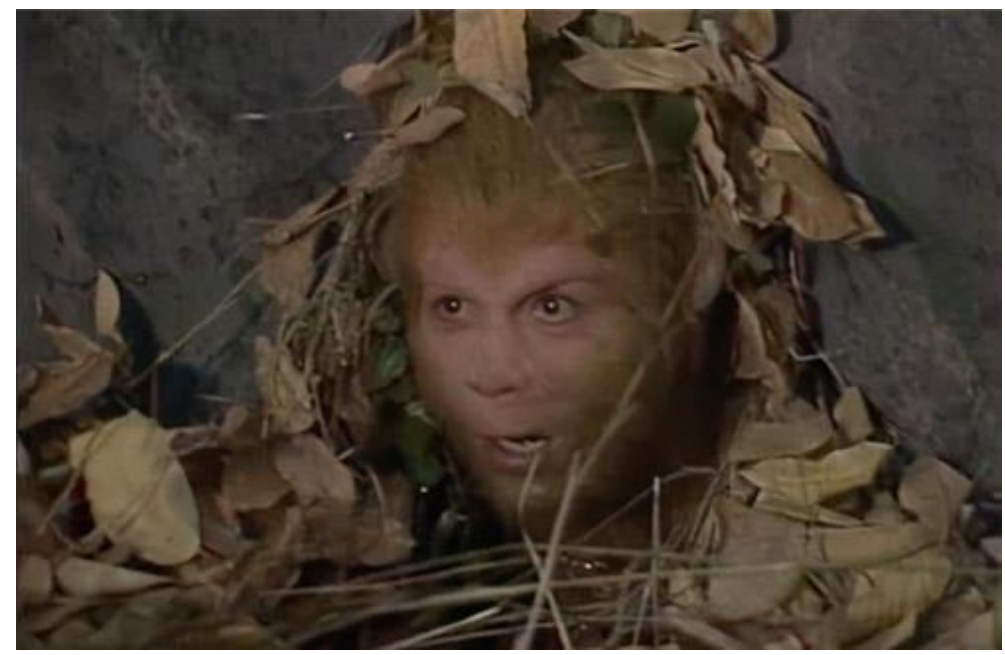

Figure 3. Sun Wukong in the movie (source: http://image.baidu.com).

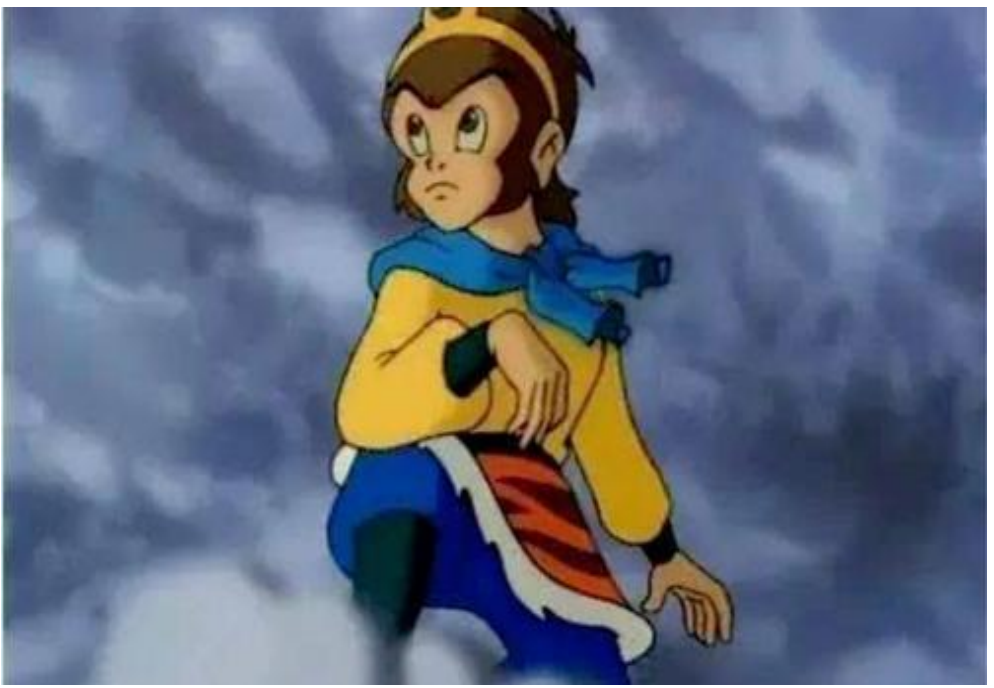

Figure 4. Sun Wukong in the animation (source: http://image.baidu.com).

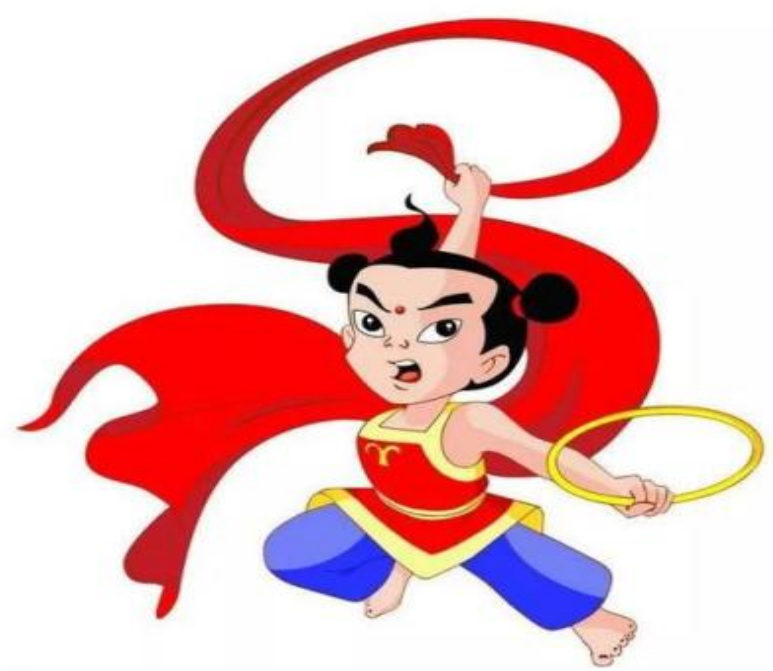

Figure 5. Ne Zha Conquers the Dragon King (source: http://image.baidu.com). 


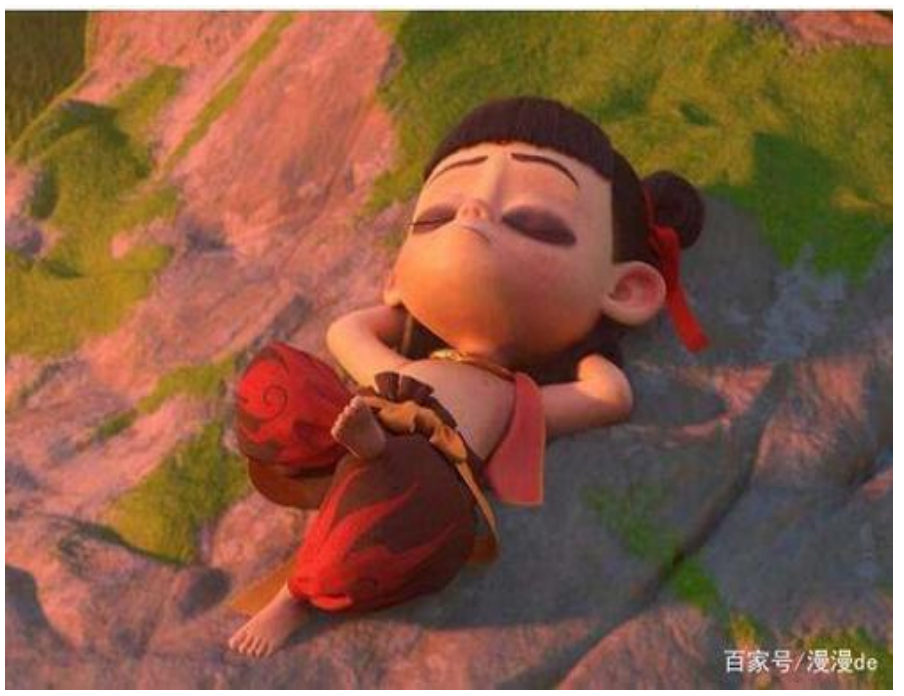

Figure 6. Ne Zha: I am the Destiny (source: http://image.baidu.com).

new traits (Li, 2010: p. 81).

In this context, the discussion of animated films should not only be made upon the story, or mythologic story, but upon the exploration of its signified expressions. Just as armor in Western movies implicates bravery, kingship represents power, bears can become a synonymous meaning of friends, etc., they condense filmmakers' creative ways to achieve specific emotion the audience might need (Li, 2010: p. 81). In China, a large number of animation films being taken from Chinese myths has triggered filmmakers to think about who shall be Chinese characters and what exactly is meant by these Chinese characters. The next section will focus on the analyses of how Chinese myths are used to create animations, so as to explore why Chinese mythology prompts cultural inheritance in China.

\section{Analyses of Chinese Cultural Elements in Animation Films}

As mentioned in the previous section, Chinese animated works are drawn from Chinese myths and legends, and the structure of the story is derived from Chinese classical themes, leaving a lasting impression on the audience. It is arguably to say that every step of the animation works reflect the greatness of Chinese culture. Take "Silk Roads" for example, it not only tells historical culture, but also shows exotic cultural features, inspiring the creators to make qualified films.

In the storyline of a number of excellent Chinese native animations such as The Princess of Iron Fan (1941), The Monkey King (1964), Ne Zha Conquers the Dragon King (1979), and Nine Colored Deer (1981), they have transmitted the conception of 'rebirth'; a term can also be read in ancient Greek mythologies. However, such re-birth is not literally expressed as similar as reborn, but is understood as the pursuit of the good, the true, and the beautiful to awaken people's inner spirit (Jiang, 2016: p. 8). For instance, the image of Ne Zha attached with the lotus is a typical plot in Ne Zha Conquers the Dragon King. It 
expressed a unique relation between life and death. That is to say, the film told audience how the two terms twisted and transferred in the process of reaching one side to the other side. Such transmigration implies that the rebirth is the chance given to good people only. Likewise, Nine Colored Deer used Dunhuang murals to tell the audience how the deer was betrayed by the farmer she helped before, and how she decided to use her divine power to get rid of a risk from an evil. Such "punitive justice" can be obtained in view of Buddhist as well as theological thoughts. Both Ne Zha Conquers the Dragon King (Figure 7) and Nine Colored Deer (see Figure 8) offered fight scenes in the animations, despite a dynamic setting of the characters, the plots may emphasize a common saying in the world: "Good will be rewarded by good, and evil with evil", advocating audience to discover the beauty of human nature. Perhaps "the beauty of human

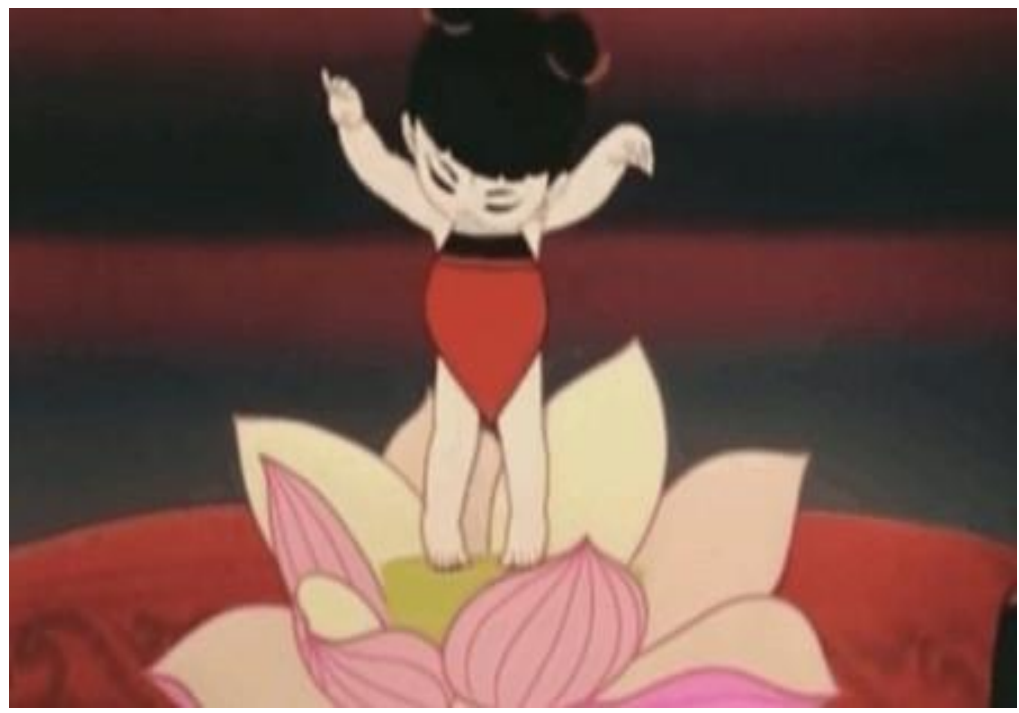

Figure 7. Ne Zha Conquers the Dragon King (source: http://image.baidu.com).

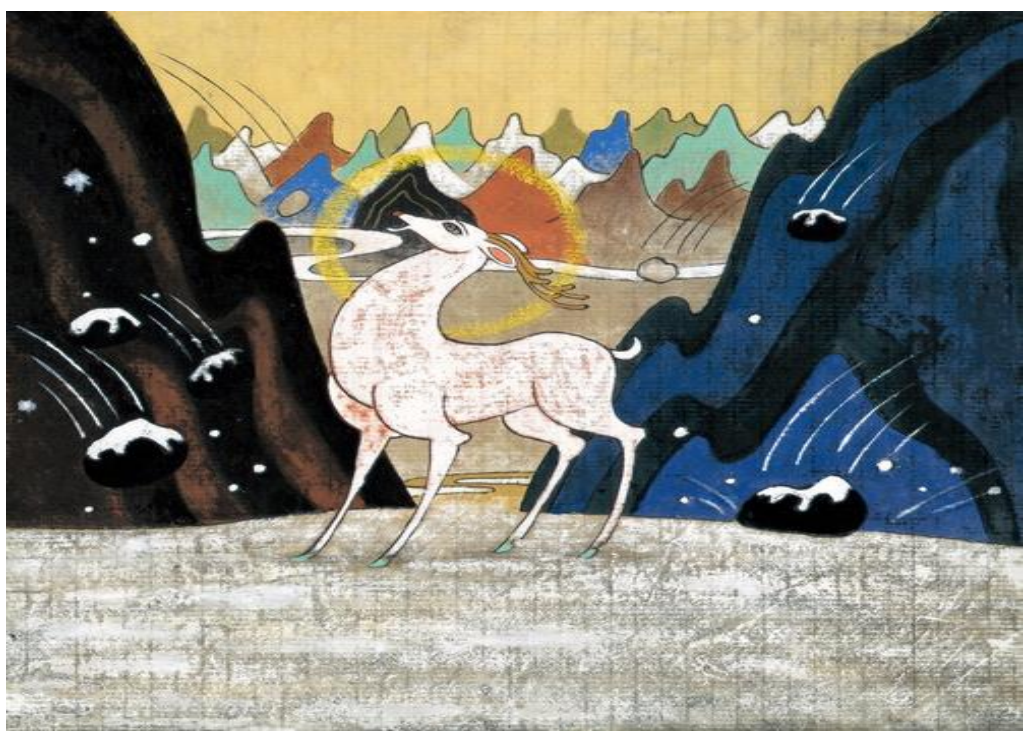

Figure 8. Nine Colored Deer (source: http://image.baidu.com). 
nature" is an ideological-based cultural heritage that the Silk Roads have brought about in the world.

In addition, the art of animation is one of the manifestations of visual culture. In the process of the development of Chinese animation films, filmmakers have made a lot of attempts in their visual expressions. For instance, there are a lot of digital technologies used in the White Snake (2019); but after watching the animation, audience can feel the beauty of the Chinese style water-ink painting, e.g., the film brushed diverse blue colours to describe water and sky; it used white color for snake, red for leaf and green for mountains (see Figure 9 and Figure 10). What these series of pictures formed is not only the environment but also mental landscapes (Zhang, 2019: p. 166). The multi-layered dark blues drew as the setoff of that lonely boat, floating in its waterway to foreshadow the separation in between white snake and A Xuan. However, the film makes red as its main tone, coupled with round-shaped mountains, claiming a reunion-based happy ending.

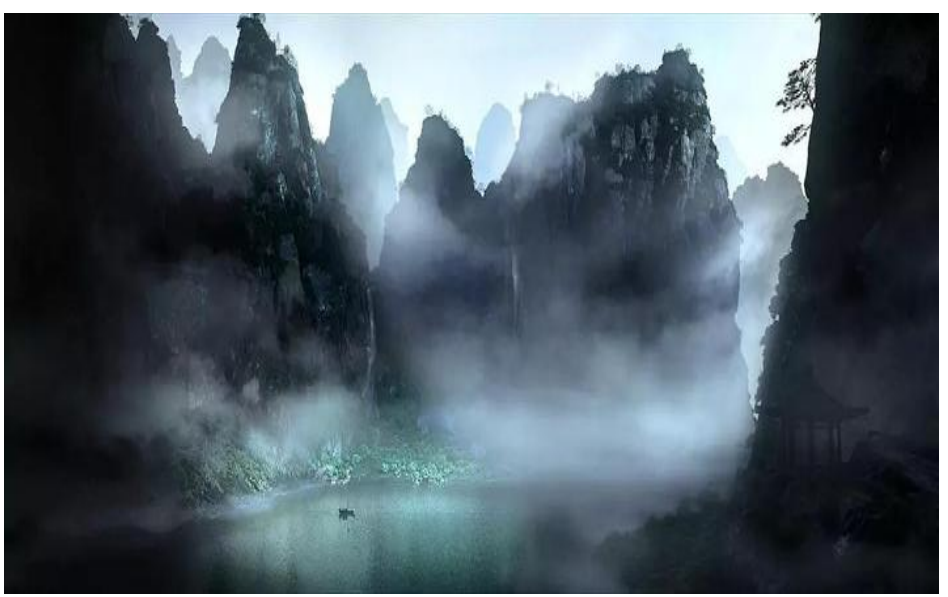

Figure 9. The use of blue colours in White Snake (Source: http://image.baidu.com).

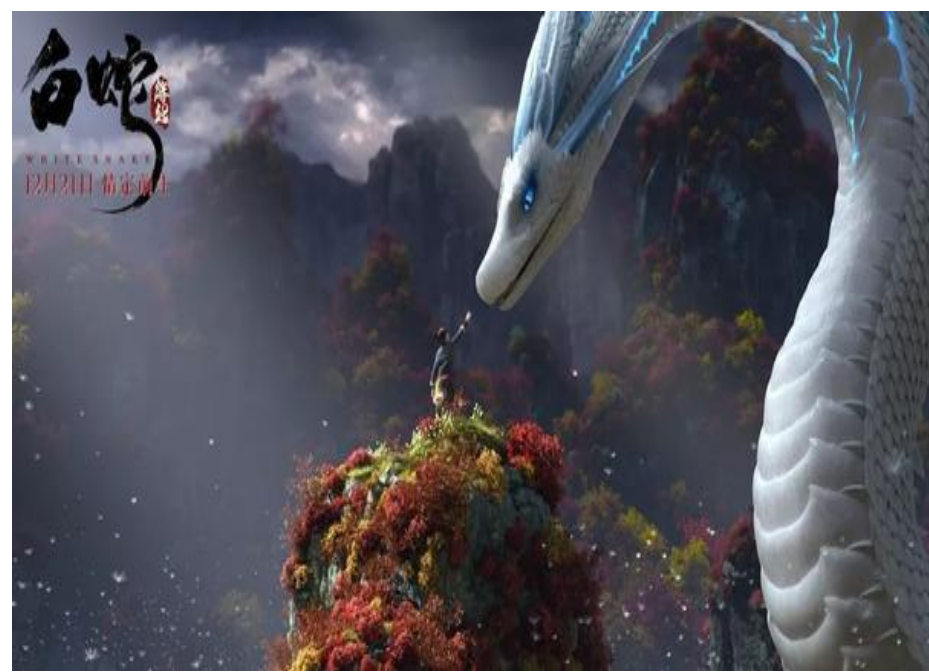

Figure 10. The use of red, white and green colours in White Snake (source: http://image.baidu.com). 
Meanwhile, the animations advanced color grading in both saturation and contrast, such as a full screen red flame in Big Fish \& Begonia (2016) (see Figure 11 ), and a contrast of red (Ne Zha) vs. white (Ao Bing) (see Figure 12) in Ne Zha: I am the Destiny (2019). These innovations have created aesthetic characteristics, along with new spiritual temperament in artistic philosophy of Chinese animation. They abandoned the conventional narration of myths and legends, by shaping new and remodeled animated characters to interpret Chinese spirit. In other words, the progress of the animations lies in their adding new roles to traditional characters; the aim is to interpret different understandings and to respect for differentiation of the social reality of China (Xue et al., 2006: p. 85).

From the success of Monkey King. Hero is Back, to the later on higher box office works such as White Snake and Ne Zha: I am the Destiny we can see that, domestic filmmakers start to rethink about the function of Chinese School in

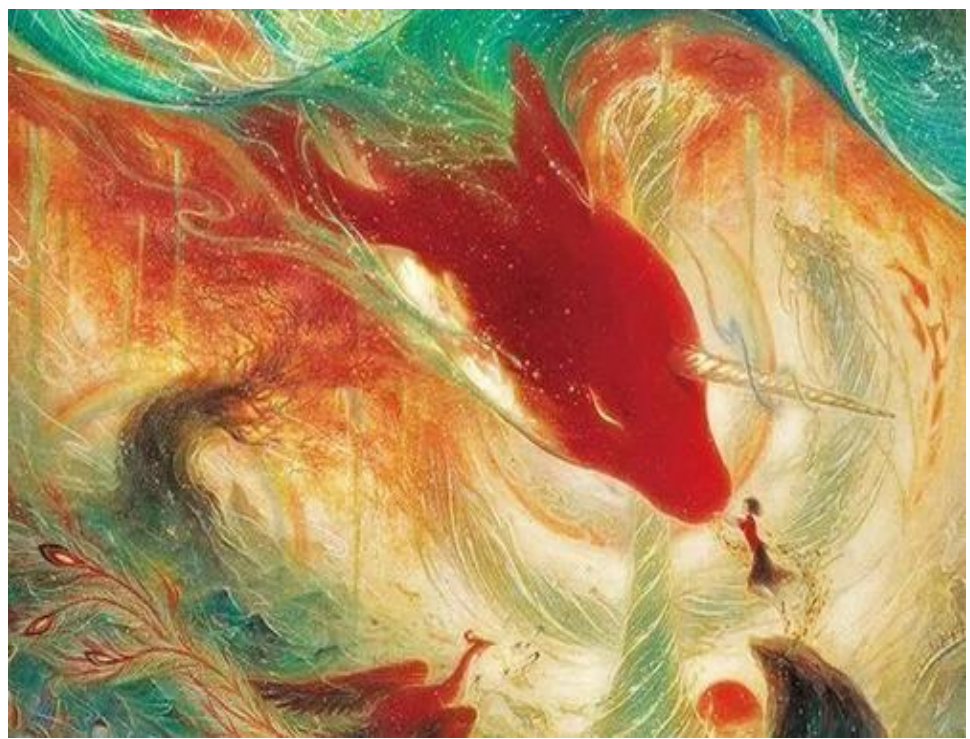

Figure 11. The use of red flame in Big Fish \& Begonia (source: http://image.baidu.com).

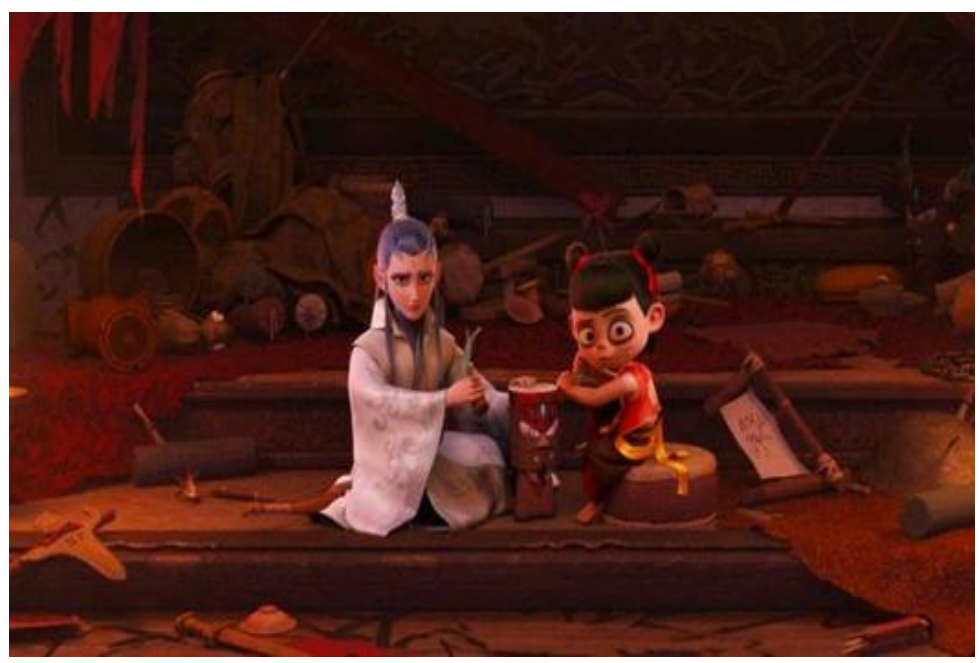

Figure 12. The use of red vs. white in Ne Zha: I am the Destiny (Source: http://image.baidu.com). 
doing animations. This means that, contemporary Chinese animated films reflect traditional Chinese cultural concepts and values, then the goal of making animation might be that, to creatively integrate the essence of Chinese culture into the process of film-making.

\section{Reinventing Animated Characters by Chinese School}

From the above analyses we can see that, Chinese mythology contains Chinese cultural roots, cultural characteristics and cultural values, affecting the creation of animated characters in Chinese animation films. The process of the effect can be divided into three layers of evolution in China's animated history. Early Chinese animation is more likely to have conversations with children, for instance, Little Tadpole Looks for Mommy (1961) and Mu Di (1963) used simple storylines to tell children the importance of protecting animals as well as environment in daily life. In this sense, the making of the animation has a certain function for education.

In addition, Chinese mythology has a certain sense of charm that audience see Chinese stories not only to be adapted into Chinese animations, but also into Disney style cartoons. For instance, hero-based images in Chinese narrative stories have been displayed in several American movies. Take Kung Fu Panda for example, although Bao in the film (see Figure 13) reveals a strong individualism advocated by American culture, the cartoon borrowed a series of Chinese cultural elements in the movie. Both Kung Fu and Panda can be seen as typical symbols of China: the former is probably an embodiment of Chinese heroes; the latter adopts what some might see as an enviable lifestyle among Chinese youngsters: eating and lying around all the time. While the character of Bao follows the Chinese-style moral code such as son should respect father and man should take responsibilities (Yan \& He, 2014: p. 22), thus, Bao becomes a true and visible hero in the public eye.

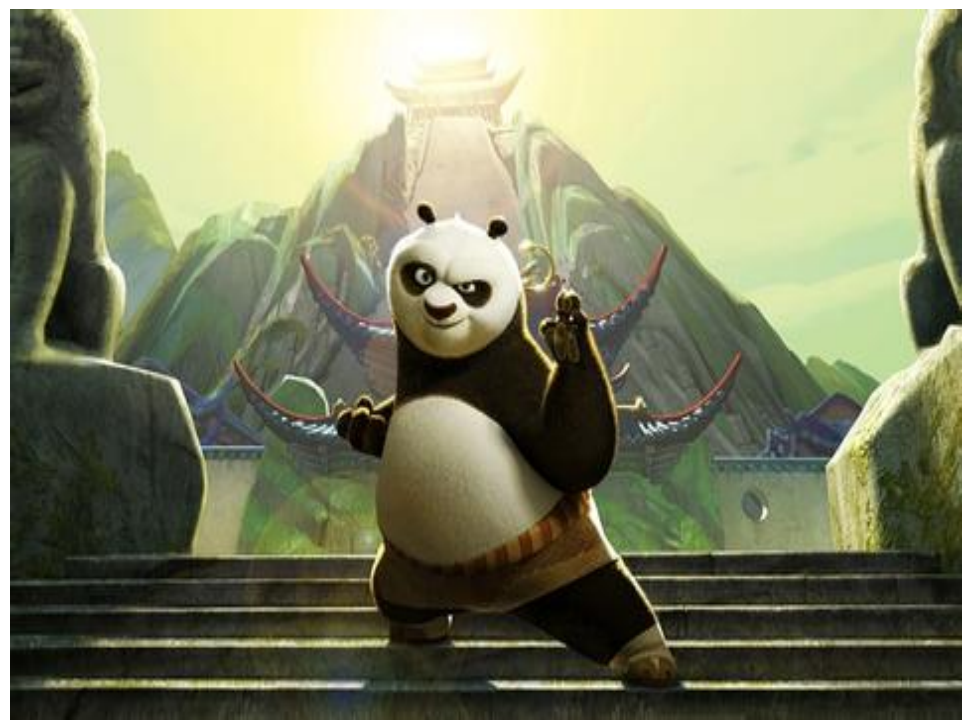

Figure 13. Bao in Kung Fu Panda (source: http://image.baidu.com). 
The image of Bao in Kung Fu Panda also has an impact on Chinese animations. The 2015 Monkey King with higher box office shaped Sun Wukong as an ordinary individual instead of a perfect hero (see Figure 14), who could be

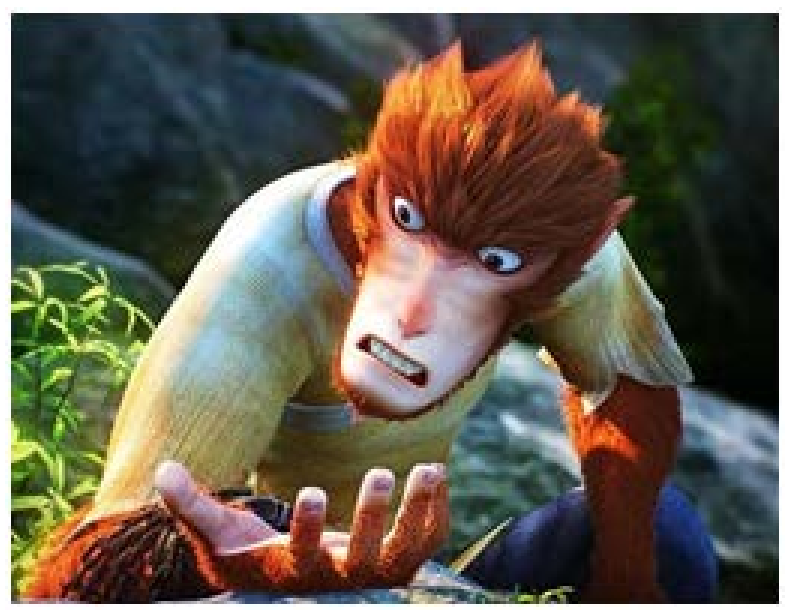

Figure 14. Sun Wukong in Monkey King. Hero is back. Source: http://image.baidu.com.

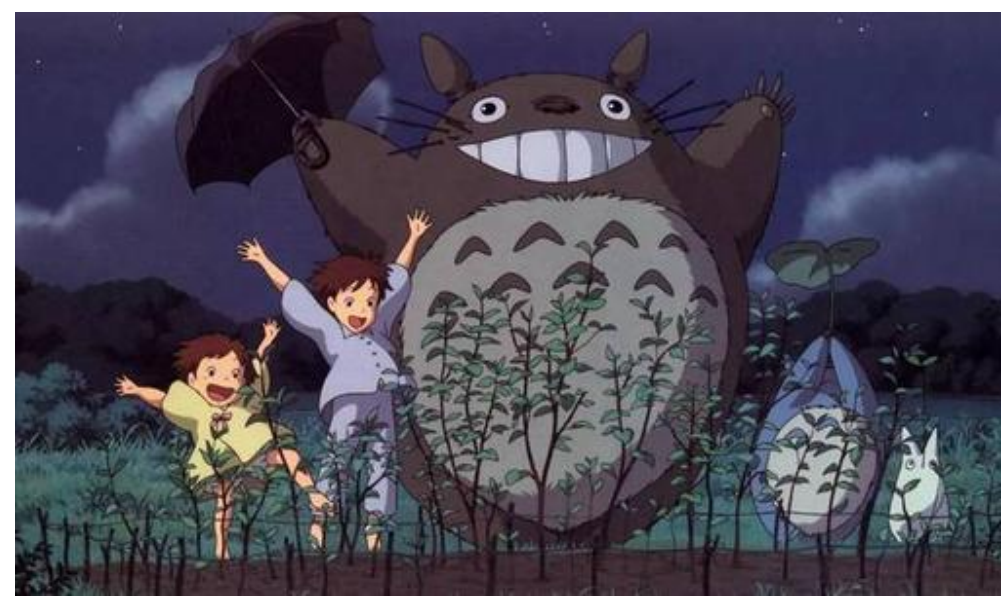

Figure 15. My Neighbour Totoro. Source: http://image.baidu.com.

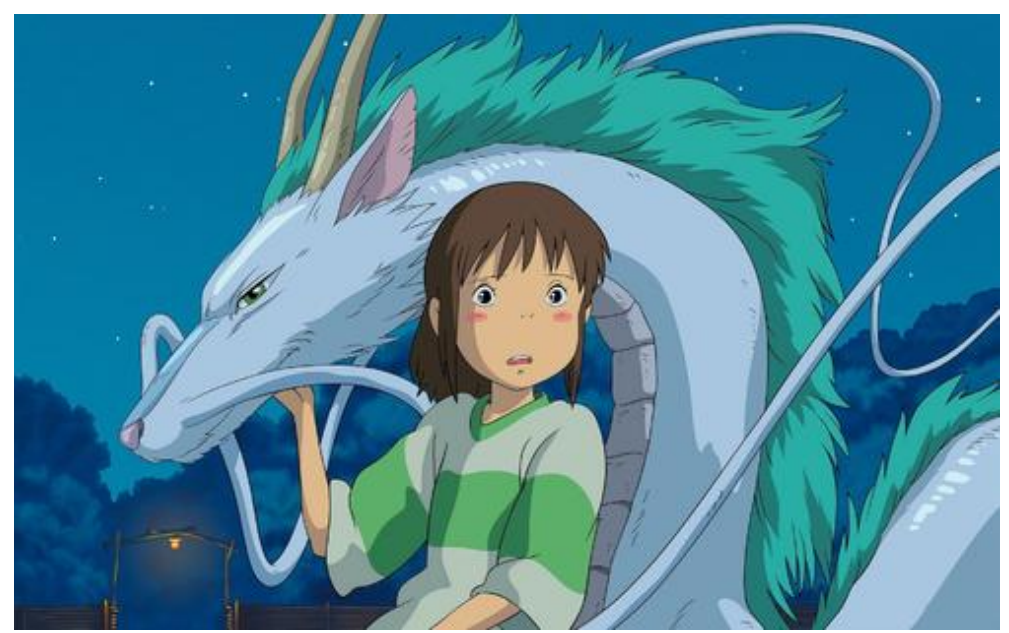

Figure 16. Spirited Away. Source: http://image.baidu.com. 
suffering, struggling and hesitating in his daily life.

Not only American cartoons, Japanese anime has a very mature model in terms of producing their animated works. Audience are very familiar with Japanese style animations partially because the filmmakers respect their folk culture; for example, lots of Miyazaki's animated works are known as unique as they are formed by hand-painted expressions such as My Neighbour Totoro (1988, see Figure 15) and Spirited Away (2001, see Figure 16). These animations narrate local stories, along with the use of Japanese line-art-based design for characters so that audiences can immediately recognize them as Japanese animation films (Chen, 2017: p. 374).

Frankly speaking, the development of Chinese animations is inevitably affected by Japanese and American styles; they have impacted on Chinese traditional values in telling Chinese stories at some point. Japan's experience in rationally using national cultural styles to create animations has given practical insight to Chinese animation filmmakers.

Besides Ne Zha Conquers the Dragon King and Nine Colored Deer, animated

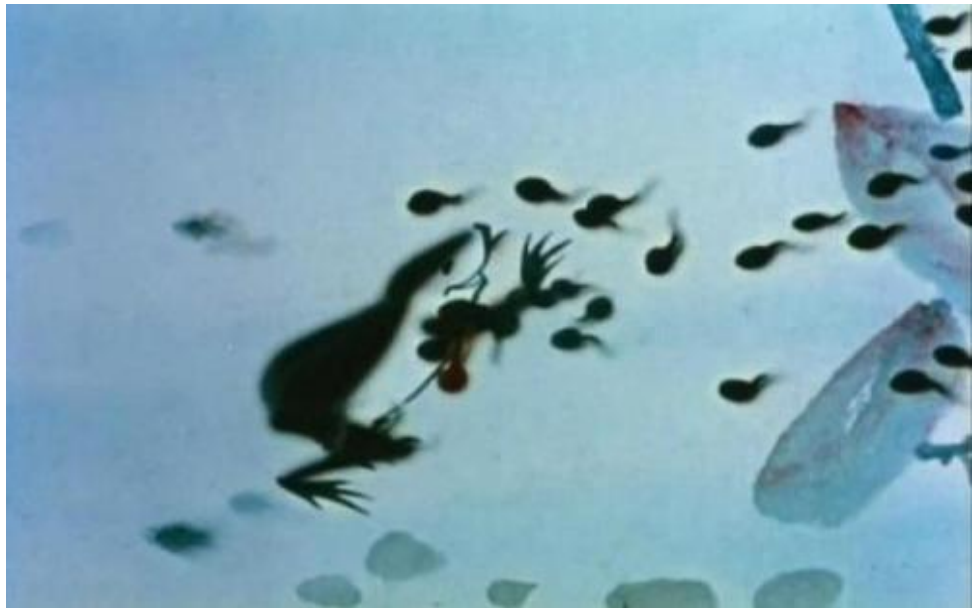

Figure 17. Little Tadpole Looks for Mommy (source: http://image.baidu.com).

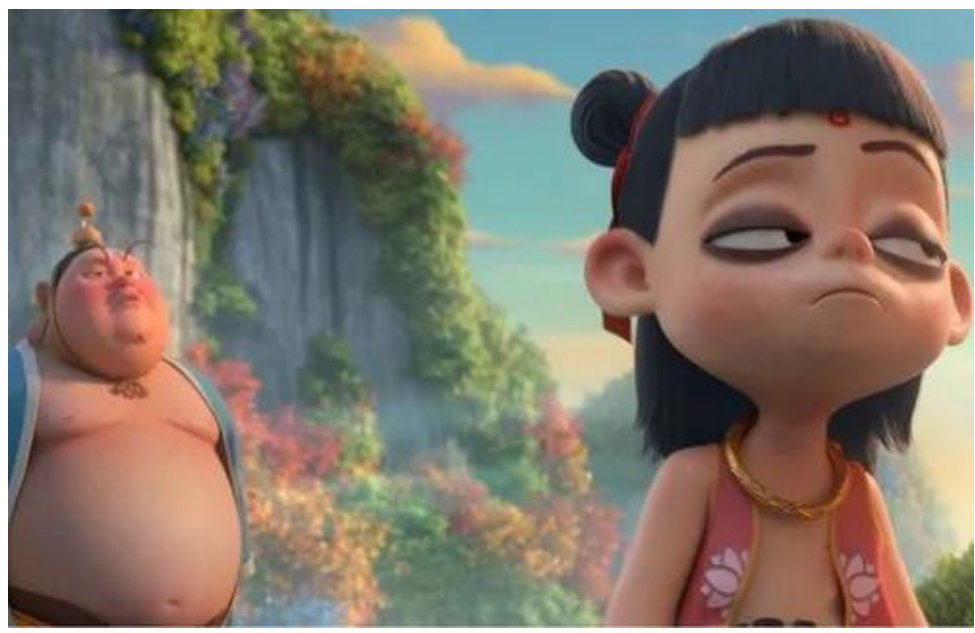

Figure 18. Ne Zha: I am the Destiny (source: http://image.baidu.com). 
works such as The Story of Any Lift (1979) was from Uighur folks, Shui Lu was adapted from a folklore of Taiwan (1985), and The Legend of the Water-splashing Festival (1988) depicted the life style of the Dai people. Stories from ethnic minorities have given Chinese animators the impetus to make more works, allowing audience to see that animations can take a variety of roles and possibilities. As Qin Xiaolin argued:

Animations become an indispensable part in film industry. They are no longer made for children but for adults as well, as they bring about greater joy for sharing and imagination to life (Qin, 2019: p. 87).

From the early work such as Little Tadpole Looks for Mommy (1961, see Figure 17) to the recent Ne Zha: I am the Destiny (2019, see Figure 18), audience may appreciate the excellent works with both classical watercolor and modern exaggerated comic features of the Chinese art forms; such appreciation also coincides with the Chinese School, their ideas of creating qualified animations. In other words, Chinese animation filmmakers have realized that the precondition for making a good film is based upon how to preserve the conventional as well as how to apply modern technologies into animated works. As Jiang Yanqin noted that:

Creation no longer simply means to keep originality or to discover the newness; it means that to generate or to find something differently from learning from each other, or communicating with each other (Jiang, 2018: p. 136).

In this sense, the producing of a new animation can be done based on an existing story, but it won't be narrated as same as its previous ones. The newness shall be something in relation to a series of 'acceptance', including the acceptance of storytelling, the acceptance of the portrayed characters, the acceptance of artistic styles, the acceptance of the use of technology, the acceptance of audience, and the acceptance of the market. All of which can be seen as important elements for Chinese School to get rid of the imitation of foreign animated works, the purpose is to strengthen China's national culture, to discover the value of Chinese animation, and to promote a sustainable development of the Chinese School so as to reinvent the form of cultural identity in film-making.

\section{Conclusion}

This paper aims to critically think about the relations between mythologies and animated films, by situating them in historical and cultural contexts of China. From the continuation of the narration of stories, to the practical usage of artistic aesthetics, to the comparison of Chinese animation with Japanese and American animated works, Chinese filmmakers have revealed audience diverse types of visual culture between motion and still, classic and modern, or dream and reality. Therefore, the notion of the "relation" in this paper is not simply to connect animation with mythology, rather, it functions as a method, and a new 
perspective to think about Chinese film history and culture beyond any creative forms. In other words, by exploring the persistent yet obscure presence of Chinese animation in its previous and recent works, this paper aims to explore the essence of understanding Chinese animations on where they come from and how they work in Chinese contexts.

First of all, the Chinese context means that, Chinese animation films are selected from the traditional mythologies. The exploring of the Silk Roads, the remodeling main character of the old Chinese stories, and the applying of artistic Chinese styles can be seen as symbolic cultural elements, while they also represent the next wave of storytellers, animators and producers, as Chinese animation talents of the Chinese School, to bring new characters and stories to life (Liu \& Deng, 2021: p. 138).

Second, the Chinese context also means to make Chinese animation differently from foreign works. The Monkey King in 2015 and the Ne Zha in 2019 immerse Chinese spirit, Chinese values, as well as Chinese styles into the animation, potentially prompt China's discourse of power in cultural inheritance ( $\mathrm{Li}$, 2019: p. 53).

Last but not least, the producing of Chinese animations shall not be understood as a narrow sense of creation. That is to say, artists, artistic works, and the development of artistic styles cannot be isolated from a communicative system (Guo \& Li, 2017: p. 117). The stress on uniqueness of a Chinese animated work means to absorb and learn from other experiences, or the characteristics of other nations, the aim is to understand cultural identity and to seek mutual understanding in the animation industry.

\section{Conflicts of Interest}

The authors declare no conflicts of interest regarding the publication of this paper.

\section{References}

Chen, Y. (2017). A Comparative Study of Chinese and Japanese Animation Role Modeling. Journal of Jiamusi Vocational Institute, 9, 374-375. (In Chinese)

Ding, E. S. (1996). The Myth and Its Social Psychological Function. Foreign Literatures, 2, 49-52.

Guo, L., \& Li, J. Y. (2017). Animating Chinese Cinemas: A Preface. Journal of Chinese Cinema, 11, 115-122. https://doi.org/10.1080/17508061.2017.1322781

Jiang, C. (2016). The Representation of the Silk Road Culture in Chinese Traditional Animation. Art Research Letters, 5, 7-16. (In Chinese) https://doi.org/10.12677/ARL.2016.52002

Jiang, Y. Q. (2018). The National Characteristics of Chinese Animations and the Study of the Chinese School. China Textile \& Apparel Press.

Li, J. H. (2019). The Expression of the Chinese Style Animated Films. Research on Digital Media, 36, 51-53.

Li, X. (2010). The Interpretation of the $21^{\text {st }}$ Century Mythology-A Study of the Magic 
Movies of Movie Genre. Journal of Guizhou University (Art Edition), 24, 79-82. (In Chinese)

Liu, K. W., \& Deng, T. T. (2021). Awakening, Lost and Breakout: The Development of Chinese Mythical-Based Animated Films. Sichuan Drama, 2, 136-138. (In Chinese)

Luo, X. (2012). Ideological Criticism of the Mythology-based Symbolic Analysis Mode. Journal of Hunan University of Technology, 6, 130-133. (In Chinese)

Qin, X. L. (2019). Humanization of Chinese Mythology: Changes of the Animation Work by Refraction of Different Images of Sun Wukong. Movie Review, 16, 84-87. (In Chinese)

Tang, H. (2021). A Reversed Construction between Deities and Demons: A Case Study of Ne Zha: I'm the Destiny. Journal of Educational Theory and Management, 5, 50-55. https://doi.org/10.26549/jetm.v5i1.6369

Xue, F., Zhao, K. H., \& Yu, F. (2006). The Development History of Animation. Southeast University Press.

Yan, Y., \& He, C. G. (2014). Comparison of the Image of Heroes in Chinese and American Animated Films: Take Ne Zha Conquers Dragon King and Kung Fu Panda as Examples. Movie Review, 4, 21-23. (In Chinese)

Zhang, J. (2019). On the Traditional Culture and Aesthetic Construction in the Animated Film White Snake. Art Evaluation, 24, 165-168. (In Chinese)

Zhou, Y. (2016). Understanding Marketing Content of Chinese Film Symbols in Cross-Cultural Study. Journal of Zhejiang University of Media and Communications, 23, 76-83. (In Chinese) 